\title{
Listening to the Community: Guidance From Native Community Members for Emerging Culturally Responsive Educators
}

\section{Authors: Christine Rogers Stanton \& Angela M. Jaime}

This is an Accepted Manuscript of an article published in Equity \& Excellence in Education in May 2010, available online: http://www.tandfonline.com/10.1080/10665681003719657.

Rogers, C. \& Jaime, A. (2010). Listening to the community: Guidance from Native community members for emerging culturally responsive educators. Equity \& Excellence in Education, 43(2), 188-201. http://dx.doi.org/10.1080/10665681003719657 


\title{
LISTENING TO THE COMMUNITY:
}

GUIDANCE FROM NATIVE COMMUNITY MEMBERS FOR EMERGING CULTURALLY

\section{RESPONSIVE EDUCATORS}

\author{
Christine A. Rogers* \\ Angela M. Jaime \\ University of Wyoming
}

\begin{abstract}
Critical race theory (CRT) emphasizes the importance of listening to the counter-narratives of people from marginalized groups. However, the applicability of CRT in practical settings often remains unclear for educators and scholars. This project offers not only a place for Native community members to share their experiences and ideas, it also provides practical guidance for emerging culturally responsive educators and ways to use themes from narratives to guide future scholarship. As a result of interviews with five Native community members, three themes emerged for non-Native educators working in Native communities: (a) learning from the community, (b) transforming thinking through discomfort, and (c) gaining awareness of positive values. These themes can be used to guide future projects, including reservation-based field experiences and research projects exploring educator thinking in reservation communities.
\end{abstract}

Whether they are classroom teachers, administrators, or support personnel, educators who work in indigenous communities frequently rely upon the perspectives of outsiders-curriculum experts, consultants, and researchers - to inform their work with students. This external influence extends to the interpretation of data, since data gathered in such communities is typically analyzed using externally created tools, such as statistics or critical frameworks. Throughout the

\footnotetext{
* Please address correspondence to Christine A Rogers, University of Wyoming, Dept. 3374, 1000 E. University
} Avenue, Laramie, WY 82071. Email: croger18@uwyo.edu 
data collection and the interpretive processes, the values and experiences of the community are often de-centered. In contrast, listening to the Native ${ }^{1}$ community throughout the research process alters the way we-as teacher educators, scholars, and teachers — view educational theory and practice. The goals of this project focus on hearing the stories of community members and learning from those stories about ways to support the development of culturally responsive educators.

The project begins with community member experiences as a means to connect indigenous community values with educators who are striving to become culturally responsive. In addition, the themes identified by the community members form a framework to guide future projects, from the interpretation of preservice field experience journals to the planning and facilitation of professional development workshops for practicing teachers. Through semistructured interviews, Native community members and elders provided guidance for non-Native educators regarding the process of becoming culturally responsive in classrooms serving Native children. This guidance, as well as the process employed to hear the community members' stories, is beneficial for not only educators but also for educational researchers and the coordinators of field experiences in teacher education.

\section{THEORETICAL FRAMEWORK}

Our work draws from critical race theory (CRT), which emerged out of legal studies as a response to "doctrinal" approaches to policy (Ladson-Billings, 1999, p. 212). Critical race theorists argue that scholars must purposefully question the dominant culture process of conducting research with an eye toward its potential to reinforce injustice. For example, critical race theorists note that the emphasis on "scientifically based research" devalues the experience of minorities, individuals, and cultural or ideological outliers given its near-exclusive attention 
on quantitative methods. With regard to the Native community, as well as to other minority communities, de-emphasizing the experiences of those outliers translates to a continued silence regarding social justice transformation in schools. As a response, critical race theorists propose a focus on those outlier experiences, especially as they directly counter dominant culture ideology (Ladson-Billings \& Tate, 1995). In education, this confrontation must occur at two levels. First, scholars must re-envision the process of collecting and interpreting data regarding teacher thinking (Kincheloe \& McLaren, 2005). Second, counter-narratives should "jar dysconscious racism" for dominant culture educators (Ladson-Billings \& Tate, 1995, p. 58).

In order to hear these counter-narratives and effectively challenge the dominant views of research and education, critical race theorists argue that researchers must actively center the culture of diverse peoples through a focus on several tenets: the exposure of racism and privilege, the use of counter-narrative to legitimize the voices of diverse peoples, and a call to social action (Ladson-Billings, 1999; Vaught \& Castagno, 2008). These tenets are interconnected in that counter-stories may be dominant culture teachers' first exposure to concrete examples of how racism and privilege materialize in their own classrooms. In many cases, accessing these counter-narratives is one of the greatest challenges. Changing classroom practice as a result of counter-stories is even more challenging.

Critical race theory has been criticized as lacking "the systemic structure" (Trevino, Harris, \& Wallace, 2008, p. 9) necessary to form strong analytic tools that can promote action. This is especially true when the experiences of the Other (the cultural insider) and the experiences of the learner (the member of the dominant culture), differ. To further complicate matters, the interpretation of these experiences can carry the weight of power and privilege if the researcher is also a cultural outsider (Bergerson, 2003; Sleeter, 1994). In addition to the concern 
that privilege and power will actually be perpetuated through research, fear of overstepping (Bergerson, 2003) or offending colleagues or participants of color may drive white scholars to inaction. However, for researchers to ignore the influence of difference contradicts the core of CRT: overlooking such difference is a privileged view that perpetuates injustice (Bergerson, 2003). Acknowledging the tension between the experiences of cultural outsiders and the perspectives of cultural insiders is the first step toward critical, societal transformation and toward a new understanding in order to critically interpret the thinking of the outsider-educator in the community of the "Cultural Other" (Montecinos, 1995, p. 291).

Re-envisioning education and educational research has been a long time coming in Native communities. Historically, Native students faced forced assimilation into dominant culture most famously as a result of the boarding school movement (Klug \& Whitfield, 2003). Children were stolen from their communities and forced to cut their hair, dress in European style clothing, and sever all connections with their language and culture as a means of “deculturalization” (Tejeda, Espinoza, \& Gutierrez, 2003, p. 33). Even in reservation-based schools, assimilative practices were, and continue to be, powerful tools of cultural and intellectual colonization. Throughout the history of Native education, the Native experience has been largely ignored. Native students and community members are only recently beginning to share counter-narratives as a means to critique the assimilative practices of the boarding schools (Simon \& Smith, 2001; Wilson, 2005).

Today, education continues to be a force of colonization in terms of U.S. education generally (MacGillivray, Ardell, Curwen, \& Palma, 2004). In Native communities, colonization is especially powerful, given the history of forced assimilation and the potential for intergenerational and historical trauma (Klug \& Whitfield, 2003). In a basic sense, teachers hold 
a power over students, manifested through the emphasis on learning English (Asher, 2009), through selection of curricular content that is passed as knowledge from educator to learner (Gandhi, 1998), and through a continued focus on instructional approaches that traditionally support Westernized, Eurocentric views of learning (Clark, 2004). Even educators who strive to be responsive often find themselves assimilated and assimilating since they feel forced to follow the rules of teaching as defined through state and national mandates. Additionally, educators may be unfamiliar with responsive pedagogy and how to transform theory to practice in their own classrooms and communities. A practical discussion regarding the potential for transformation is a missing link in schools (hooks, 1994).

Furthermore, respecting the values of the indigenous community and collaborating with Native participants throughout the research process and beyond is essential to promoting decolonization of scholarship through counter-narratives (Battiste, 2007; Bishop, 2005; Smith, 1999, 2005). Through hearing the stories of Native participants, we can learn about practical ways to change our teaching and scholarship, therefore better responding to the needs of our Native students while preserving the values of the community. While several works incorporate the counter-narratives of Native peoples to encourage enhanced responsive education (Cleary \& Peacock, 1997; Klug \& Whitfield, 2003), the application of these works in research and teacher preparation settings remains only minimally explored.

\section{METHODS OF INQUIRY}

To guide our inquiry into community views of culturally responsive education, we conducted semi-structured interviews with five Native community members. Questions included: "What are your goals for non-Native preservice teachers on the reservation?" and "What can non-Native educators do to be culturally responsive practitioners?" as well as questions about 
goals for Native children. At our request, the first two community members recommended the involvement of the three additional participants. The initial interviews were audio recorded and ranged from one to two hours in length. We knew all of the informants due to previous work in the communities on and near the reservation, allowing for continued dialogue after the interviews.

All interviewees, three women and two men, were or are involved with education on the reservation in some way, as educators, administrators, parents, former students, and/or grandparents. The conversations centered upon discussion of developing culturally responsive educators. To ensure the anonymity of the community members, we used pseudonyms throughout the transcription and reporting stages. We are also vague in our description of the community and schools to protect the identity of individuals and their families. Native communities are small environments and are easily identifiable because of size and location.

As we reviewed the transcripts, we physically coded responses on a line-by-line level (Emerson, Fretz, \& Shaw, 1995; Rubin \& Rubin, 2005). Following initial coding, we identified responses that participants emphasized most, whether it was during a single, extended response or during shorter, recurring examples. In addition to comparing responses within each interview, we compared responses across interviews as we formed larger categories (Rubin \& Rubin, 2005). Finally, we conducted member checks with participants throughout the process via faceto-face meetings and/or emailing (Merriam, 2002).

After interactions with participants and analysis of the data, we identified three themes that can influence understanding about the development of emerging culturally responsive educators : (a) Learning from community mentors: “Teach me," (b) Transforming thinking through discomfort: "Witness something," and (c) Gaining awareness of positive values: "I am 
not conquered." For each theme, we include an introduction to the theme and community member description of the goal for emerging responsive educators.

Learning from the Community: "Teach me."

For four of the five interviewees, learning from the Native community was a vital component of truly responsive teaching. The community members emphasized the importance of observing culturally responsive educators in action, dialoguing with elders and Native educators, and asking questions of educators, parents, and students. In some cases, educator interest in the community can even generate renewal of language and tradition for students.

Teachers need to over and over, just say, "Learn your language" and "Learn your culture" or say "Teach me." "What do I need to know to be able to become part of this community? Teach me something about ..." (Norman)

Norman's involvement with the Native American Church and ceremonies keeps him grounded in tradition. Family is central; his work with schools on and bordering the reservation are, to an extent, driven by his role as a father and husband. For Norman and several of the other participants, cultural outsiders can and should promote cultural and linguistic rejuvenation in Native communities. The key is to develop meaningful and respectful relationships with community members. Of course, this relationship-building demands extensive time:

It [the relationship with the community] takes years to build up. There was a [nonNative] teacher and something [in the classroom] happened. And she went straight to the [family's] house. And those people, they did not like that. I think it scared them. When somebody comes to your door and says, "Your son did this." It turns them off. They took their kids and went to [another school]. Don't expect change right then and there. If you 
see something, then slowly work on it. Or else ask somebody "How should I go to the house?" (Marie)

The time needed for cultural outsiders to establish trusting relationships in Native communities is a challenge for many teacher education programs. Even long-term field experiences are often too limited to successfully connect non-Native preservice teachers with mentors in the community.

Evelyn agreed that relationships take extensive time and energy to cultivate, but she is optimistic about teacher-community partnerships and about life in general. Her determination and optimism helped Evelyn earn a college degree while preserving her cultural status in the community. As Marie explained, this is very difficult, since many Native people who leave the reservation are no longer viewed as insiders. As an educator and parent, Evelyn is very aware of the challenges facing Native children and their educators, especially about "walking in two worlds." Instead of thinking of experience on the reservation as a stepping stone to another job, she "would like to see preservice teachers take time to become aware of our students" needs and become part of the community." For Evelyn, the time needed to develop educator-community relationships or at the least to recognize how to begin building those relationships should be a vital component of field experiences.

Thomas, another educator who has succeeded in two worlds, has become very familiar with teacher education programs. He explained that when non-Native educators and community members join together, "Something happen[s]. We start connecting." Initiating the formation of these connections in the short amount of time provided by a field experience is challenging. Several community members offered ways to promote basic connections, including facilitating home stays with families, touring of the tribal cultural center, and participating in elder-led orientations to the "history of each tribe and the traumatic events they went through." In addition 
to seeking relationships with community members, emerging culturally responsive educators should learn about the value of collegial relationships in schools. This comprehensive relationship development takes active participation, initiative, and patience in order to connect the classroom to the community. Norman stated, "You've got to sit down and meet and talk eye to eye ... and not just in one or two meetings ... Bring in educators who are Native American, let them be a part of that."

\section{Transforming Thinking Through Discomfort: "Witness something."}

Several of the community members explained that feeling some discomfort could prove transformative for the non-Native preservice teachers within the context of a short, introductory field experience. While some dis-ease is expected in any new situation or experience, the community members emphasized that transforming thinking and understanding is closely tied to gaining what can be a very painful awareness of difference. For non-Native preservice teachers, this often includes an awareness of difference that exposes their white privilege - an awareness that can invoke feelings of guilt, confusion, or anger. In some cases, this discomfort may be due to an emerging awareness of the real challenges facing educators and children in reservation communities.

You're going to run into people who are poor, who happen to be Indian. There are folks who might be homeless. They might not have any parents. They might be coming from a home that's got alcohol or drug problems. Or they might be in a house that's got health problems, like diabetes . . So, when you say, “Oh, bring a box of cookies for class tomorrow," a lot of those kids aren't going to have enough [money] for that, and they may not show up. So, just be aware. You might want to take a better look at things you want to do. (Thomas) 
Thomas radiates amazing energy. His dedication to improving education and opportunities for people on the reservation runs deep. He is an educator, an activist, a parent, and a grandparent. His positive outlook allows him to succeed on two levels—culturally and physically—at the same time: the Native community and Western society. For Thomas, one of the most valuable insights the preservice teachers can gain during a field experience on the reservation is to be open to seeing something "you never saw over [in the university community]" and to adjust your thinking about classroom pedagogy as a result.

Most of the informants emphasized the importance of witnessing something new and of becoming aware of the challenges facing Native children. Rosebud explained, "instead of getting mad at the kid or blaming the kid, maybe you should think there could be something else going on here." Marie, an elementary teacher, parent, and grandparent, suggested that educators modify their teaching instead of expecting the children to change something they do not understand.

They [preservice teachers] need to understand that the students are struggling at home.... A lot of them are kind of lost. I think that if you have a student in your class that you can't understand and you don't know where they're coming from, don't give up on them.... The average university student, they don't know what it is like. They never had to go without food. These kids [on the reservation], they have to look for food and sometimes they don't find any. (Marie)

As Marie noted, and other participants echoed, gaining new awareness is not confined to learning about cultural differences. For some children on the reservation, culture and economics may be intertwined. However, recognizing challenges does not give teachers the license to assume their students are doomed to a cycle of poverty or that they cannot learn. Marie also argued that instead of assuming that poverty or racism automatically lead to academic problems, teachers' 
failure to believe in their students can be the cause of those academic, social, and economic challenges. Rather than blaming a concept like poverty, which is abstract to middle-class teachers, educators should critique the power of their assumptions regarding student potential. That's why so many people are a failure, why they dropped out of school. Somebody back there didn't see their potential.... That's where it all starts—in elementary school. So they go to alcoholism, they go to suicide. They say, "I'm no good," and they believe it.... I see it. It's personal to me. It's family. People are dying from it. I have so many relatives who aren't here anymore. And they were so young. They should be here. Education, elementary school, is so important. It's so important. It's the beginning. (Marie) Marie emphasized that teachers thinking about student potential can affect students early in their educational careers. Educators who show that they believe in students have a long-lasting impact on those children. Thomas explained that students "will remember that.... They keep that for years. If somebody says they are good at something, then they begin to believe it .... They remember that."

While field placements can provide experiences that highlight the potential of students, and while they may transform stereotypes in positive ways for the majority of preservice teachers, they also have the potential to move some future teachers away from culturally responsive teaching and social justice. Several participants explained that transformations will not occur in all cases and that support for new teachers is needed to avoid "scaring them off" (Thomas) and to promote positive change. Although transformations may occur from learning about the real challenges facing students in reservation schools, providing opportunities for new teachers to discuss these challenges with Native mentors is essential so that the discomfort does not simply result in fear and confusion. Teacher educators and mentors should provide guided 
opportunities for emerging responsive teachers to begin thinking about those challenges and their implications for student learning.

I think [the field experience] is really beneficial. It's not going to give them [preservice teachers] insight to every minority group, but it may help them understand diversity better. Especially if it's not their environment — do you understand what I mean? It's not where they grew up or what they're used to. They're being introduced to a different culture and a completely different environment. I think it's beneficial especially for [preservice teachers] who have preconceived notions about Native culture. I'm not saying all of them are going to come out changed or completely different, but it can get them to thinking. (Rosebud)

Encouraging educators to think about cultural and socioeconomic diversity, while potentially uncomfortable, is the vital first step of transformative, critical thinking (Mezirow, 2003). The community members explained that this discomfort really opens educators' eyes. Mentor teachers, teacher educators, and community members can provide opportunities for preservice teachers to openly discuss and reflect on this discomfort through journaling and focus group discussions.

\section{Gaining Awareness of Positive Values: "I am not conquered."}

Sharing the challenges of life on the reservation is only one slice of the experience, as several of the community members emphasized. Evelyn explained, " [Preservice teachers] can learn to be aware of not only our social ills, like many other communities', but what we have to offer as far as generosity and kindness with our people." Norman and Thomas both explained that preservice and early career teachers should be paired with dedicated mentor teachers who 
model integration of positive community values, who participate in community events, and who view teaching as more than just a job.

Modeling the integration of positive values in the classroom is a key part of what defines a responsive educator. The community members hope new teachers will utilize Native culture and language within instruction and demonstrate an appreciation for cultural sustainability. However, successful application of these values in future classrooms depends on more than effective modeling in field experiences. Educators must transform their thinking about the relevance of culture in schools. For example, if they recognize the role of the extended family, they can build upon the existing support structure in the community. For Marie, an awareness of the positive influence of the tribal community can ignite a transformation in thinking.

Little six-year-olds, they don't know about attitude. They're just now learning. Exploring. I know where those kids are coming from. If you're trying to give up on this little guy, you don't know the whole story! And that's what I think the preservice teachers need to realize. It's not just this little guy. He's got a big long line of [relatives and community members] behind him. And he is surrounded by all these people. (Marie) Marie was very passionate, especially about teaching and culture, and her eyes glistened with tears as she described the children she has known. Although she is strongly supportive of culturally responsive education, she is caught in an exhausting dilemma. As a Native woman who believes deeply in her traditional ways, she does not question authority, so she does not challenge administrative decisions, such as the adoption of standardized curriculum programs, even though she worries about how she can connect with students' cultural ways of knowing within such rigid and structured programs. She does the best she can. She holds her students to very high standards, and she loves them unconditionally and completely. Other participants 
emphasized the importance of love and respect within and beyond educational contexts. For Rosebud, a former student of both reservation and border town school systems, responsive teachers must recognize and respect the community, and the students in particular:

You have to go in there with a lot of respect. I'm not saying that preservice teachers don't have respect. But on the reservation, you have to respect the community, you have to respect the parents. You have to respect all of that. And you have to respect the kids most of all. (Rosebud)

Supporting students was a central theme for all of the community members. The participants shared their hope that Native children in their community would not only finish high school but also that they would pursue higher education. Despite this hope, several of the community members explained that many Native children are taught that they are not smart enough to go to college.

That shouldn't be taught from the time we're little kids, that "college isn't possible for you." Why not have the possibility? Maybe that's too clean cut and ice cream happy, but you know what I mean? I just don't think it's fair to put a child into that and make them feel so low. I heard that from so many of my cousins. When I was graduating [from high school], and they asked what I was going to do, and I told them that I was going to college, they said, "Wow, I wish I was that smart, to go to college" and it's like, "you ARE.” It shouldn't be taught that you aren't smart enough. (Rosebud) For several of the interviewees, college, when combined with preservation of tradition, supports cultural survival since it provides access to dominant culture power systems. Norman summarized his confidence in the survival of his people as connected to practicing traditional ways while learning about dominant culture systems: "I am not conquered." For Norman, 
understanding his identity within the context of dominant culture results in power that supports cultural survival and change. All of the interviewees hoped that during reservation-based field experiences preservice teachers would gain an awareness of this strength and that this understanding would influence and transform their future teaching in their own classrooms. We need to educate [new teachers]. There are Indian people here and we're not going to go anywhere. We're going to be here tomorrow. We're going to be here. I think that's where we start talking about understanding that process.... That's our land right there. That's our water running by. We're in a tough situation. And the sad part is we've been pushed "out of sight, out of mind" for so long. And things were taken from us. Our language, our religion, our grandparents, our children — they took our children away from us. And on top of that they come to us and ask, "What's wrong with you? Why can't you read?" (Thomas)

This awareness of survival and emphasis on believing in students appeared throughout every interview. Rosebud noted, "My culture's always going to be there, as long as I keep involving myself with my community and remembering who I am." For many of the community members, family and community cultivate cultural survival.

The family is probably the most important thing. Even for those who don't have a family. The tribe is so strong, so unified, that if something happened, we all come together. If you need help, you don't have to go very far. All you've got to do is tell someone you need help. It's so strong. So positive. A lot of communities across the world have lost that, but we still have that. I don't believe it will go away. (Marie)

Pride and tradition bond the members of the community together, as Marie noted: "We have our beliefs. Our Native religion is so strong. Like Sundance. Our sweats. Our holy people. 
It's a very strong community." This understanding of the traditional ways of the people can foster respect, which, in turn, can lead to support of culture and language in the classroom. Several of the participants emphasized the importance of teacher involvement in the community as a means to develop an awareness of these positive values.

[New teachers] need to get to know the background of Native American kids and the community. That's the most important thing. Play a big part, be at powwows, be at some of the ceremonies if they are invited.... Be seen out in public.... It tells [Native students] that [educators] really care, that they are involved. They want to be involved. They don't want to be [the type of teacher who leaves] when the bell rings at 3 o'clock ... and that's it. (Norman)

For educators who are actively involved in the Native community, teaching is not just a job. Instead, it is a way of life. Good educators, "show up every day" (Thomas) and are committed to learning about the culture of their students. "Education doesn't have to be a negative thing" (Rosebud) for the educators or the learners; it can be a powerful and positive force for students, educators, and the community as a whole.

\section{DISCUSSION}

In order to recognize and value education as a positive force, educators must fully hear the counter-narratives of Native community members. This means we must go beyond gathering the stories, since that process has historically hinged upon outsider interpretation of the information. The ways we interpret, share, and apply those stories are also critical. For example, as a part of reservation-based field experiences, preservice teacher journaling can be interpreted using a framework developed from this project in order to evaluate whether or not preservice teacher views of experiences align with community member suggestions. Such co-constructed 
interpretive frameworks are one way to re-theorize critical race methodologies (Solórzano \& Yosso, 2002) while promoting expanded understandings as opposed to narrow, individualized interpretations. As a part of our research process, we collaborated with Native community members - cultural insiders - to generate a set of expectations for responsive non-Native educators serving Native children. These expectations can help guide planning and facilitation of field experiences, professional development, and future research focusing on teacher thinking.

First, the community members explained that effective educators are simultaneously committed to their own learning and to the success of all of their children. Since critical race theory relies heavily upon recognizing experiences that have been historically ignored, this continued learning is vital for future teachers who are cultural outsiders working in diverse communities. In addition to expanding culturally responsive curricula within teacher education programs, preservice teachers should have access to multiple field experiences, including longterm internships, in reservation communities. Furthermore, continued dialogue with people from diverse backgrounds could promote enhanced learning for emerging responsive educators, regardless of the number of years they have been teaching. These teachers should engage in community driven mentorships, attend tribal events, live and shop in the community, and participate in culturally responsive professional development. This is especially important for early career educators.

This career-long learning is the essence of the first theme, learning from the community, and it centers on educators recognizing the importance of connecting with community members both in and beyond the school walls (Nieto, 2004; Phillips, 1995). In providing field experiences that can initiate a transformation in educator thinking while aligning with the themes of critical theory, the community members suggested that field experiences model school-community 
partnerships to support preservice teachers who may not be able to envision the connections in practice. In addition, providing future teachers with cultural mentors who can continue to guide their learning in future years is essential. Field experiences should also strive to carefully match teachers with responsive mentor teachers who are incorporating culture and language extensively to avoid a belief that passivity toward cultural difference is acceptable in schools serving Native children. Teacher educators and mentor teachers should share specific relationship-building skills with educators while providing time devoted to networking and reflection. Early career teachers should engage in mentorships with experienced teachers who are recognized as responsive by the community. In addition, teaming new teachers with community mentors could provide support for efforts to learn about the community and to respectfully integrate culture and language into the curriculum. Such mentorships would be beneficial for emerging culturally responsive teachers at all stages of their careers, whether they have 2 or 22 years of teaching experience. Administrators and school board members can further cultivate responsiveness through community-based professional development, mentorship programs, and incentives for educators to engage in community involvement and responsive coursework.

The second theme, which centered on introducing emerging responsive teachers to the challenges facing Native children, focuses on the need for non-Native educators to experience a transformation in thinking about culture as a result of witnessing the real challenges facing Native children. Given the potential discomfort associated with transformative learning, the participants emphasized that supportive guidance is needed to avoid "scaring [non-Native preservice teachers] off' and perpetuating or creating misconceptions about Native culture. The distress is the first step toward advancing the goals of CRT and promoting social change, since transformative learning hinges upon experiential discomfort (Mezirow, 2003). The interviewees 
suggested that follow-up experiences, added coursework, and continued dialogue with community members could help support responsive transformations in emerging responsive teachers' thinking. Again, building lasting mentorships is an essential component of successful experiences that can support the development of emerging culturally responsive educators.

In addition to gaining an introduction to the challenges facing Native peoples, community members want educators to recognize positive aspects of Native culture. Considering the complexity of cultural, political, and economic aspects on the reservation, this goal can be exceptionally challenging. For example, while teacher educators and other mentors should not downplay the challenges associated with poverty on the reservation, it is important to encourage new teachers to recognize the potential for classist thinking about teaching and learning. It is dangerous for teachers to fixate on any one area of challenge, since it can overshadow the positive aspects. The community members suggested that respect for the positive impact of traditional tribal values can encourage educators to believe in the potential of their students (,Lee, Gabbard, \& Reyhner, 1993). Although a transformation in thinking is often triggered by an uncomfortable or distressing situation (Mezirow, 2003), an emphasis on the positive aspects of culture, such as support from extended family, pride in traditions, and cultural sustainability, potentially advances the goals of critical theory more effectively for those preservice educators who initially carry negative misconceptions with them into the field. For example, teacher educators and mentors should discuss the supportive role of extended family and share strategies for involving parents, grandparents, aunts, uncles, and cousins in the educational experience.

Learning that promotes social justice hinges upon actively seeking an awareness of the experiences of the Cultural Other (Montecinos, 1995). This is the common thread that binds the goals identified by the community members. Emerging culturally responsive educators must 
strive to learn from community members, to step outside of their comfort zones, and to notice the unique, positive aspects of Native culture while acknowledging the need for their own continued, career-long learning. For the community members, these goals really all tell one story of cultural sustainability. Because of the support, challenges, values, and hopes within Native communities, individuals like the participants who contributed to the creation of this framework continue to fight for better educational opportunities for Native youth.

IMPLICATIONS: "It's the beginning"

Through listening to the counter-narratives regarding effective teaching that the community members shared, it became clear that they believe strongly that non-Native educators must recognize that the process of becoming culturally responsive is necessary, dynamic, and ongoing. The participants explained that a comprehensive understanding of effective and responsive teaching is not a realistic goal for a two-day immersion field experience or even for a semester-long internship. Rosebud noted, “There's so much to learn, I think it would take a lot longer." The community members emphasized that they hoped emerging culturally responsive educators would be able to recognize ways to continue learning through coursework and additional field experiences. "Take advantage of courses that might be offered in the community [i.e., Native education, language, or history courses offered on or near the reservation] to better understand where we are" (Thomas). Coursework specifically tailored to working with Native children can help to connect theory to practice for non-Native preservice teachers. Coursework is most effective if it includes "something real" as part of the experience (Thomas). For example, teacher educators could provide opportunities for future teachers to hear the stories of Native peoples through panel discussions. To further connect real experiences to understanding, teacher 
educators or practicum supervisors could ask students to compare and contrast the reservationbased field experiences with prior field experiences.

In order to make the coursework meaningful, several of the community members explained the importance of keeping an open mind to new learning as an educator, which demands careful self-reflection on the part of teachers. Some educators believe they are openminded because they do not assume negative stereotypes to be true. However, responsive teachers have to be careful that they do not ignore the challenges that face Native students, and that they do not make incorrect assumptions. Rosebud's high school teachers assumed that since she had many non-Native and Native friends that she was somehow more successful at "walking in two worlds" than some of the other Native students attending bordertown schools. In reality, Rosebud has faced many challenges throughout her education. Teachers questioned her beliefs and asked her to be a spokesperson for all Native peoples. Many of these teachers were likely trying to be culturally sensitive as they did this. They probably believed that inviting Rosebud to share a cultural perspective demonstrated their interest in diversity and culture. Unfortunately, their invitation often resulted in a sense of pressure to share indigenous knowledge as a minority member of a predominantly non-Native class, which demonstrates the instructors' limited awareness of Native epistemologies and the diversity between tribal groups, not to mention Rosebud's unique personality.

Another potential problem occurs when non-Native teachers bring cultural topics into the classroom inappropriately. For example, the participants explained that some teachers discuss Native ceremonies without guidance from elders. The teachers in these cases may believe they are connecting to Native culture within the context of a specific subject area, but they potentially overstep their bounds when they teach about information that should only be shared by elders 
within the context of traditional practice. While the informants thought that some non-Native educators have overstepped their bounds in terms of respectfully integrating Native culture into their classrooms, most praised teachers who ask questions of parents and elders and who use open-ended projects that encourage students to incorporate culture or language. This inclusion can encourage a renewal of cultural and linguistic pride, which can generate confidence and success in all aspects of life. Several of the participants shared stories about educators who believe in their students and who help their students believe in themselves. These educators are vital for the community and the continuance of the Native culture, regardless of their own cultural backgrounds. School districts, teacher education programs, and communities should support the development of responsive educators through cultivating respectful collaboration between community and schools.

Scholars and teacher educators can learn from the three themes in several ways. First, collaborating with community members throughout the research process and educational planning is important. Second, scholars must utilize accessible formats to share their work in order to provide a connection between the community and non-Native teachers by honoring counter-stories. It is also essential to build future projects upon community member's counterstories. Linking research efforts together can provide a clearer picture of theory/practice intersections. Future work regarding teacher experiences and educator thinking in and near tribal communities should consider analyzing data of community member-generated expectations.

When considering change of a critical and intercultural context, authentic transformation occurs when the altered perceptions of the outsiders (in this case, the non-Native preservice teachers and the non-Native researcher) demonstrate respect for and understanding of the views and goals of the insiders (the Native community members). Instead of separating non-Native 
educator experiences and Native counter-stories, developing a set of interpretive guidelines with community members could help bridge teacher stories and community counter-stories in a way that transforms practice in classrooms.

For example, we plan to explore preservice teacher field journals for descriptions that support the three themes we have identified through this project, as well as passages where the educator journals potentially conflict with community values. Such analysis allows us to continuously monitor the effectiveness of our teacher education programs and field experiences. While the specific themes here cannot be generalized to all Native communities, the process we utilized to develop the framework is potentially applicable in many settings. As scholars and teacher educators, we must continue to speak with community members regarding field experiences, teacher thinking, and education as empowerment for Native children. Our work can never be finished.

The insights shared by community members in this project provide a starting point for the design of field experiences and for practicing teachers to reflect on their culturally responsive teaching in the classroom. It is important to note that the conversations and resulting themes are potentially tied to colonization. To fully consider this possibility through a CRT lens, we must determine the influence of the education and experiences of the community members. Since the community members involved in this project are able to navigate successfully in "two worlds," there is potential for dominant culture thinking to have influenced their beliefs. Despite this, developing an interpretive framework driven by community member identified themes can provide a way to begin connecting CRT to non-Native educators' thinking and practice. Instead of interpreting data from the outside in, using a pre-existing lens, we advocate that scholars position the insider's perspective at the center of their interpretive framework. According to 
Thomas, educators, communities, and teacher educators stand at a critical point in connecting theory to action:

There's a lot of good ideas out there. There's a lot of good people. Something's not happening the way I feel it should. Our kids are still failing. Look at how many years. Look at how many potential teachers that we had, or potential English professors, that are lost. Some of our eighth graders have dropped out already. That's sad. That kind of hurts right here [points to heart].

\section{REFERENCES}

Ashcroft, B., Griffiths, G., \& Tifflin, H. (1995). The postcolonial studies reader. New York: Routledge.

Asher, N. (2009). Writing home/decolonizing text(s). Discourse: Studies in the Cultural Politics of Education, 30(1), 1-13.

Battiste, M. (2007). Research ethics for protecting indigenous knowledge and heritage: Institutional and researcher responsibilities. In N. K. Denzin \& M. D. Giardina (Eds.), Ethical futures in qualitative research: Decolonizing the politics of knowledge (pp. 111132). Walnut Creek, CA: Left Coast Press.

Bergerson, A. A. (2003). Critical race theory and white racism: Is there room for white scholars in fighting racism in education? Qualitative Studies in Education, 16(1), 51-63.

Bishop, R. (2005). Freeing ourselves from neocolonial domination in research: A Kaupapa Maori approach to creating knowledge. In N. K. Denzin \& Y. S. Lincoln (Eds.), The Sage handbook of qualitative research ( $3^{\text {rd }}$ ed., pp. 109-138). Thousand Oaks, CA: Sage.

Clark, D. A. T. (2004). Not the end of the stories, not the end of the songs: Visualizing, signifying, counter-colonizing. In D. A. Mihesuah \& A. C. Wilson (Eds.), Indigenizing 
the academy: Transforming scholarship and empowering communities (pp. 218-232).

Lincoln: University of Nebraska Press.

Cleary, L. M., \& Peacock, T. D. (1998). Collected wisdom: American Indian education. Boston: Allyn \& Bacon.

Emerson, R. M., Fretz, R. I., \& Shaw, L. L. (1995). Writing ethnographic fieldnotes. Chicago: University of Chicago Press.

Gandhi, L. (1998). Postcolonial theory: A critical introduction. New York: Columbia University Press.

hooks, b. (1994). Teaching to transgress: Education as the practice of freedom. New York: Routledge.

Kincheloe, J. L., \& McLaren, P. (2005). Rethinking Critical Theory and qualitative research. In N. K. Denzin \& Y. S. Lincoln (Eds.), The Sage handbook of qualitative research $\left(3^{\text {rd }}\right.$ ed., pp. 303-342). Thousand Oaks, CA: Sage.

Klug, B. J., \& Whitfield, P. T. (2003). Widening the circle: Culturally relevant pedagogy for American Indian children. New York: RoutledgeFalmer.

Ladson-Billings, G., \& Tate, W. E., IV, (1995). Toward a critical race theory of education. Teachers College Record, 97(1), 47-68.

Ladson-Billings, G. (1999). Preparing teachers for diverse student populations: A critical race theory perspective. Review of Research in Education, 24, 211-247.

Lee, H., Gabbard, D., \& Reyhner, J. (1993). A specialized knowledge base for teaching American Indian and Alaska Native students. Tribal College: The Journal of American Indian Higher Education, 4(4), 26-32. 
MacGillivray, L., Ardell, A. L., Curwen, M. S., \& Palma, J. (2004). Colonized teachers:

Examining the implementation of a scripted reading program. Teaching Education, 15(2), $131-144$.

Merriam, S. B. (2002). Qualitative research in practice: Examples for discussion and analysis. San Francisco: Jossey-Bass.

Mezirow, J. (2003). Transformative learning as discourse. Journal of Transformative Education, $1(1), 58-63$.

Montecinos, C. (1995). Culture as an ongoing dialog: Implications for multicultural teacher education. In C. E. Sleeter \& P. L. McLaren (Eds.), Multicultural education, critical pedagogy, and the politics of difference (pp. 291-308). New York: State University of New York Press.

Nieto, S. (2004). Affirming diversity: The sociopolitical context of multicultural education ( $^{\text {th }}$ ed.). New York: Pearson.

Phillips, E. N. (1995). Multicultural education beyond the classroom. In C. E. Sleeter \& P. L. McLaren (Eds.), Multicultural education, critical pedagogy, and the politics of difference (pp. 371-392). New York: State University of New York Press.

Rubin, H., \& Rubin, I. (2005). Analyzing coded data. In H. Rubin \& I. Rubin, Qualitative interviewing: The art of hearing data $\left(2^{\text {nd }}\right.$ ed.,, pp. 224-245). Thousand Oaks, CA: Sage.

Simon, J., \& Smith, L. T. (2001). A civilising mission? Perceptions and representations of the New Zealand Native schools system. Auckland, New Zealand: Auckland University Press.

Sleeter, C. (1994). White racism. Multicultural Education, 1(4), 5-8, 39. 
Smith, L. T. (1999). Decolonizing methodologies: Research and indigenous peoples. New York: Zed Books.

Smith, L. T. (2005). On tricky ground: Researching the Native in the age of uncertainty. In N. K. Denzin \& Y. S. Lincoln (Eds.), The Sage handbook of qualitative research ( $3^{\text {rd }}$ ed., pp. 85-107). Thousand Oaks, CA: Sage.

Solórzano, D. G., \& Yosso, T. J. (2002). Critical race methodology: Counter-Storytelling as an analytical framework for education research. Qualitative Inquiry, 8(1), 23-44.

Tejeda, C., Espinoza, M., \& Gutierrez, K. (2003). Toward a decolonizing pedagogy: Social justice reconsidered. In P. P. Trifonas (Ed.), Pedagogies of difference: Rethinking education for social change (pp. 10-40). New York: RoutledgeFalmer.

Trevino, A. J., Harris, M. A., \& Wallace, D. (2008). What's so critical about Critical Race Theory? Contemporary Justice Review, 11(1), 7-10.

Vaught, S. E., \& Castagno, A. E. (2008). "I don't think I'm a racist”: Critical Race Theory, teacher attitudes, and structural racism. Race, Ethnicity, and Education, 11(2), 95-113.

Wilson, W. A. (2005). Remember this! Dakota decolonization and the Eli Taylor narratives. Lincoln: University of Nebraska Press.

Christine Rogers is a Ph.D. candidate in Education at the University of Wyoming. Her main research interests include community-centered scholarship and learning, critical literacy, and decolonizing education in reservation border towns.

Angela M. Jaime identifies with Pit River \& Valley Maidu tribal affiliation and is an assistant professor in Educational Studies at the University of Wyoming. Her research interests include curriculum studies, Native American and multicultural education, and ethnic studies. 
${ }^{1}$ Although it is certainly desirable to refer to Native people by their tribal names and to point out individual tribal traits, it is not feasible to do so when discussing the tribes in general. Therefore, unless noted otherwise, the terms Native, Indigenous People or Native American will be used to refer to all tribes. 